\title{
Period-doubling bifurcation analysis and chaos control for load torque using FLC
}

\author{
Eman Moustafa ${ }^{1} \cdot$ Abdel-Azem Sobaih $^{1} \cdot$ Belal Abozalam $^{1} \cdot$ Amged Sayed A. Mahmoud $^{1}$
}

Received: 1 June 2020 / Accepted: 13 January 2021 / Published online: 30 January 2021

(c) The Author(s) 2021

\begin{abstract}
Chaotic phenomena are observed in several practical and scientific fields; however, the chaos is harmful to systems as they can lead them to be unstable. Consequently, the purpose of this study is to analyze the bifurcation of permanent magnet direct current (PMDC) motor and develop a controller that can suppress chaotic behavior resulted from parameter variation such as the loading effect. The nonlinear behaviors of PMDC motors were investigated by time-domain waveform, phase portrait, and Floquet theory. By varying the load torque, a period-doubling bifurcation appeared which in turn led to chaotic behavior in the system. So, a fuzzy logic controller and developing the Floquet theory techniques are applied to eliminate the bifurcation and the chaos effects. The controller is used to enhance the performance of the system by getting a faster response without overshoot or oscillation, moreover, tends to reduce the steady-state error while maintaining its stability. The simulation results emphasize that fuzzy control provides better performance than that obtained from the other controller.
\end{abstract}

Keywords Nonlinear phenomena $\cdot$ Chaos $\cdot$ Period-doubling bifurcation $\cdot$ State transition matrix (STM) · Floquet theory $\cdot$ And fuzzy logic controller (FLC)

\section{Introduction}

Specific nonlinear dynamic system behavior is complex anomalies that can induce qualitative changes in the system's steady-state trajectory such as chaos, bifurcations, co-existing attractors, and fractal basin boundaries [1-7]. The research field of chaotic system analysis and control has seen rapid development in recent years. The chaos appears in many mechanical and electrical systems such as lasers, nonlinear optical systems, optimization techniques, biological systems, chemical reactions, cancer treatments, fluids flow, moreover, many other applications [8-16]. Practically, the

Eman Moustafa

Eman.osman88@gmail.com

Abdel-Azem Sobaih

abdazimsopeh@gmail.com

Belal Abozalam

drbelalabozalam@yahoo.com

Amged Sayed A. Mahmoud

amgad.mahmoud@el-eng.menofia.edu.eg

1 Department of Industrial Electronics and Control Engineering, Faculty of Electronic Engineering, Menoufia University, Shibin El Kom, Egypt chaos and bifurcation are harmful to these systems as they can lead them to be unstable or make undesirable behavior, so control techniques and methodologies are required to reduce or eliminate the harmful chaotic effect. Consequently, studying chaos behavior and suppressing it has been the major target of researchers for practical nonlinear systems. Consequently, there are numerous methods to control chaotic systems, such as the (Ott, Grebogi and Yorke) OGY method [31], feed-back linearization method [32-34], a realtime cycle to cycle variable slope compensation method [35], time-delay feedback control [36], developing Floquet theory [26, 30, 37-39], fuzzy control [41, 43, 45, 46].

The stability boundary of the chaotic system relies on invariant sets like equilibrium points, periodic, quasi-periodic, and chaotic orbits are representative. In this work, the periodic and chaotic orbits are investigated to study the stability behavior of the dynamic systems. Periodic orbits are powerful tools in studying and analyzing the dynamic systems as they provide a periodic solution which shows a closed orbit in phase-space. While the chaotic orbits have an unlimited number of points in the phase portrait and its trajectory is a random-like but bounded behavior and does not intersect with each other. 
The popular methods used for analyzing chaos are the Floquet theory and the Lyapunov exponent method which depends on the Poincaré map. Poincaré map creates a complex structure with a discrete state-space which is a smaller dimension than the original continuous dynamic scheme. The stability of the Poincaré map depends on the map's Jacobian matrix, but the calculation process of the Jacobian matrix may be complex. This interpretation of the Poincaré map is seldom used as it requires developing information for a limited cycle location [24, 25]. While, the Floquet theory depends on the State Transition Matrix (STM) for the full cycle [34, 35, 37-39]. Both methods give the same results; however, the Floquet theory fits well with mechanical switching systems and simpler to be implemented as compared to the Lyapunov exponent method [25-30].

Chaotic systems are deterministic, nonlinear, and very sensitive to the initial condition. Accordingly, long-term prediction of chaotic systems becomes impossible, on the other hand, they are controllable systems [17-19]. While, the change in specific behavior of the system is known as a bifurcation $[19,20]$. The bifurcation phenomenon describes the fundamental alteration in the dynamics of nonlinear systems under parameter variation. As the theory of bifurcation is a tool to help to understand equilibrium loss and its consequences for complex behavior. There are many types of periodic orbit local bifurcation such as period-doubling bifurcation, and Hopf bifurcation [20-23].

DC (direct current) motor is used in many applications and nearly most mechanical movement that can be observed around us. As it is found in several domestic appliances such as HD cameras, smart toys, mixing machines, and in advanced orthopedic bone drilling [47-51]. Recently, the analysis of the non-linear characteristic of an electric DC motor has become an emerging research topic. The drive system consists of a converter and a controller which produce pulse width modulation (PWM) to adjust the voltage value of the DC motor. PWM's switching action makes the entire drive system to be time-varying and nonlinear, because the operation of the system during the $\mathrm{ON}$ state differs from its operation in the OFF state. The nominal steady state of the PMDC drive is the period-1 orbit, but altering some drive parameters will lead to a new attracting orbit that is periodic, quasi-periodic, or chaotic [39].

Zadeh [40] introduced the fundamental of the fuzzy logic controller (FLC) in 1965, many researchers dedicated themselves to this topic to find innovative strategies for improving the performance of the FLC system and ensuring its reliability. So, FLC can eliminate the nonlinearity effects of a DC motor simply and comfortably. Designing FLC also does not need a systematic procedure or a mathematical model of a system. Besides, it improves performance and provides superior outcomes than other techniques. Hence, FLC gives better results with position control and DC/DC converters [42] and [44], stabilizes the induction motor [45], removes chaos in converters [41], and controls complicated, undefined chaotic systems Parameters [43, 46].

Most researchers deal with the impact of changing the input voltage of PMDC motors or the controller gains on the chaos behavior [20, 30, 35, 41]. Another research gap is that most control techniques deal with eliminating chaos and bifurcation without taking into consideration the performance of the system [32, 33, 37-39]. Therefore, the contribution of this work is to investigate another important factor in the PMDC motor which is the impact of changing the load torque on chaos behavior with taking into consideration the performance of the system. Through this work, the nominal state for the PMDC motor was explored while changing load torque, which results in losing stability and changing the trajectory from period-1 to period-2 orbit. Also, changing the load torque causes chaos. So, two techniques were used to overcome these problems. The first technique is developing Floquet theory, where the result shows that the system is still in period-1 (nominal state) orbit with changing the load torque and the system suffers from overshoot and oscillations. The second technique is the Proportional Integral (PI) fuzzy controller, where the simulation result shows that the system also still in a nominal state without overshoot or oscillations and eliminates the steady-state error. Simulation results were performed using MATLAB / SIMULINK software.

The outline of the paper is as follows:- the mathematical model, dynamic behavior of PMDC drive, and analysis of the stability of period-1 orbit are devoted in "Preliminaries", while "The controller" introduces the control of the system using a fuzzy PI controller and the next section summarizes the conclusion of the results.

\section{Preliminaries}

\section{PMDC drive}

In this section, the chaotic behavior in the drive system will be studied. The speed of the motor can be controlled through PWM to change the applied voltage of the armature. The PMDC motor specifications which are depicted in Fig. 1, are given as $\omega_{\text {ref }}$ is the reference speed $=100 \mathrm{rad} / \mathrm{s}$, $R$ is the armature resistance $=7.8 \Omega, L$ is the armature inductance $=5 \mathrm{mH}, K_{\mathrm{T}}$ is the torque constant $=0.09 \mathrm{Nm} / \mathrm{A}$, $K_{\mathrm{e}}$ is the back electromotive force constant $=0.0984 \mathrm{~V}$.s $/$ $\mathrm{rad}, B$ is the viscous damping factor $=0.000015 \mathrm{Nm} / \mathrm{rad} /$ sec, $T_{\mathrm{L}}$ is the load torque $=0.087 \mathrm{~N} \mathrm{~m}, J$ is the moment of inertia $=4.8400 \mathrm{e}-005 \mathrm{Nm} / \mathrm{rad} / \mathrm{sec}^{2}$ and $T$ is the periodic time $=0.05 \mathrm{~ms}$. 
Fig. 1 Circuit diagram of the permanent magnet DC drive

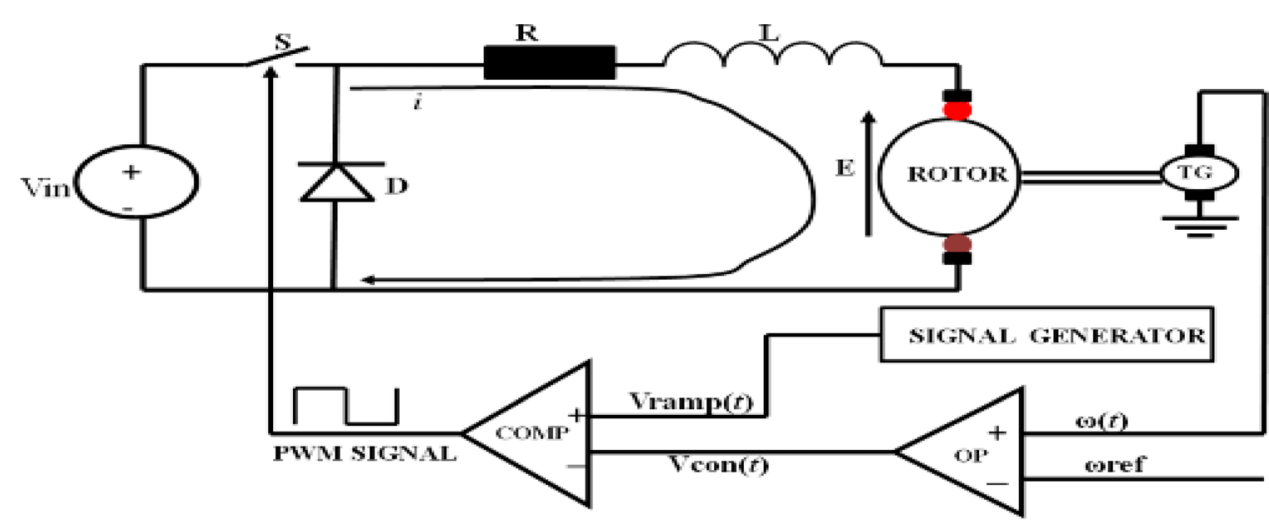

\section{Mathematical model of the system}

When the saw-tooth signal $V_{\text {ramp }}(t)$ is greater than the control signal $V_{\text {con }}(t)$, the model is described by

$\frac{d X(t)}{d t}=A_{\mathrm{on}} X(t)+V_{\mathrm{on}}$

When the saw-tooth signal is smaller than the control signal, the model is described by

$\frac{d X(t)}{d t}=A_{\mathrm{off}} X(t)+V_{\mathrm{off}}$

where $A_{\text {on }}=A_{\text {off }}=A=\left[\begin{array}{cc}\frac{-B}{J} & \frac{K_{T}}{J} \\ \frac{-K_{e}}{L} & \frac{-R}{L}\end{array}\right], V_{\text {on }}=\left[\begin{array}{c}\frac{-T_{L}}{J} \\ \frac{V_{\text {in }}}{L}\end{array}\right]$ and

$V_{\text {off }}=\left[\begin{array}{c}\frac{-T_{L}}{J} \\ 0\end{array}\right]$.

$V_{\text {con }}(t)=K_{P}\left(\omega(t)-\omega_{\text {ref }}\right)$,

where $K_{P}$ is the proportional controller gain, $\omega(t)$ is the shaft speed and $\omega_{\text {ref }}$ is the reference speed:

$V_{\text {ramp }}(t)=V_{L}+V_{D}\left(\frac{t}{T} \bmod 1\right)$,

where $V_{L}, V_{U}$ are lower and upper values of the saw-tooth signal, $V_{D}=V_{U}-V_{L}$ and $T$ is the PWM period:

$X(t)=[\omega(t) i(t)]^{T}=\left[x_{1}(t) x_{2}(t)\right]^{T}$.

\section{Dynamic behavior of the system when changing the load torque}

In this section, the time-domain waveform and phase portrait is introduced to investigate the stability and chaotic behavior of the PMDC drive. The nominal steady-state behavior of this system is period- 1 for $K_{\mathrm{P}}=1, V_{\text {in }}=24 \mathrm{~V}$, and $T_{\mathrm{L}}=0.087 \mathrm{Nm}$.

By altering the load torque to $T_{\mathrm{L}}=0.1 \mathrm{Nm}$ at time $=0.3 \mathrm{~s}$, overshoot, undershoot, and the oscillation of the system increase. Besides, the system losses its stability, and the period-doubling bifurcation occurred which is called fast scale bifurcation. The waveforms of period- 2 speed and current when changing load torque at $0.3 \mathrm{~s}$ is depicted in Fig. 2 .

A further variation of the load torque $\left(T_{\mathrm{L}}=0.11 \mathrm{Nm}\right.$ at $0.6 \mathrm{~s}$.) increases the settling time and the period-doubling bifurcation leads to chaos, as presented in Fig. 2. Such nonlinear phenomena can lead the system to dangerous or disastrous conditions. Hence, these nonlinear phenomena should be reduced as much as possible. Also, Period-1
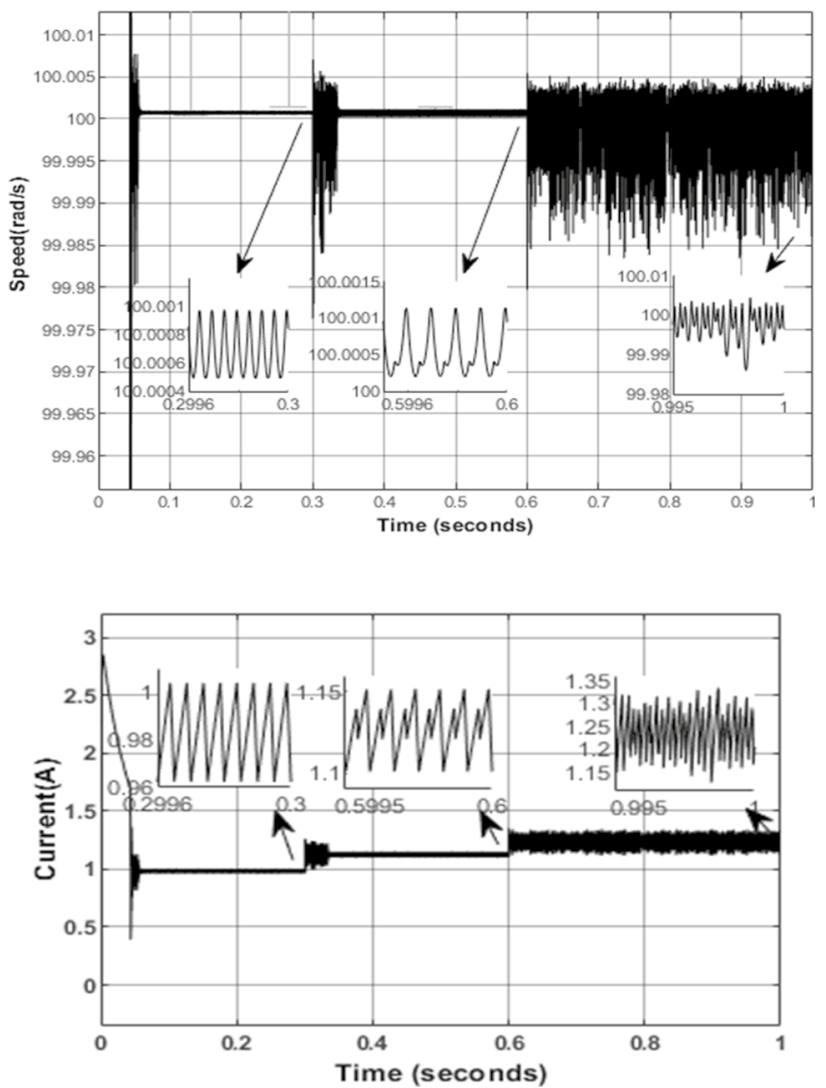

Fig. 2 Waveforms for speed and current at $K_{\mathrm{P}}=1, V_{\text {in }}=24 \mathrm{~V}$ with changing load torque 
at $T_{\mathrm{L}}=0.087 \mathrm{Nm}$, period -2 at $T_{\mathrm{L}}=0.1 \mathrm{Nm}$, period- 4 at $T_{\mathrm{L}}=0.1045 \mathrm{Nm}$, and chaos at $T_{\mathrm{L}}=0.11 \mathrm{Nm}$ trajectories (phase portraits) are presented in Fig. 3 .

\section{Analysis of the chaos}

Analysis of Chaos using Floquet theory was discussed in [25-30]. Floquet Theory (Filippov's method) is applied to analyze the stability based on Floquet multipliers ([34, 37, 38] and [39]). Monodromy matrix is shown equally:

$M(T, 0)=S_{2} \times \Phi\left(T, t_{\varepsilon}\right) \times S_{1} \times \Phi\left(t_{\varepsilon}, 0\right)$,

where $S_{1}$ is the Saltation matrix when the path transfer from the cut-off region to the saturation region, $S_{2}$ is the Saltation matrix when the path transfer from the saturation region to the cut-off region, and $\phi\left(t_{y}, t_{x}\right)$ is the STM from $t_{x}$ to $t_{y}$, where $\Phi\left(t_{y}, t_{x}\right)=e^{A\left(t_{y}-t_{x}\right)}$ :

$S=I+\frac{\left(f_{+}-f_{-}\right) n^{T}}{n^{T} f_{-}+\frac{\partial h(X(t))}{\partial t} \mid t=t_{\varepsilon}}$,

where $n$ is the normal vector, $f_{-}$and $f_{+}$are vector fields previously and next switching moment, $I$ is the unit matrix, $h=V_{\text {con }}-V_{\text {ramp }}, \frac{\partial h}{\partial t}=\frac{-\left(V_{U}-V_{L}\right)}{T}, f_{+}=A_{\text {on }} X\left(t_{\varepsilon}\right)+V_{\text {on }}, f_{-}=A_{\text {off }}$ $X\left(t_{\varepsilon}\right)+V_{\text {off }}$ and $n^{T}=\left[K_{P} O\right]$.

The trajectory will be stable if all modulus of the Floquet multipliers is less than 1 and unstable if one of the modulus greater than 1 . The results presented in Table 1 show that the trajectory loses its stability when $T_{\mathrm{L}}=0.1$ $\mathrm{Nm}$, the same as the result obtained from waveforms.

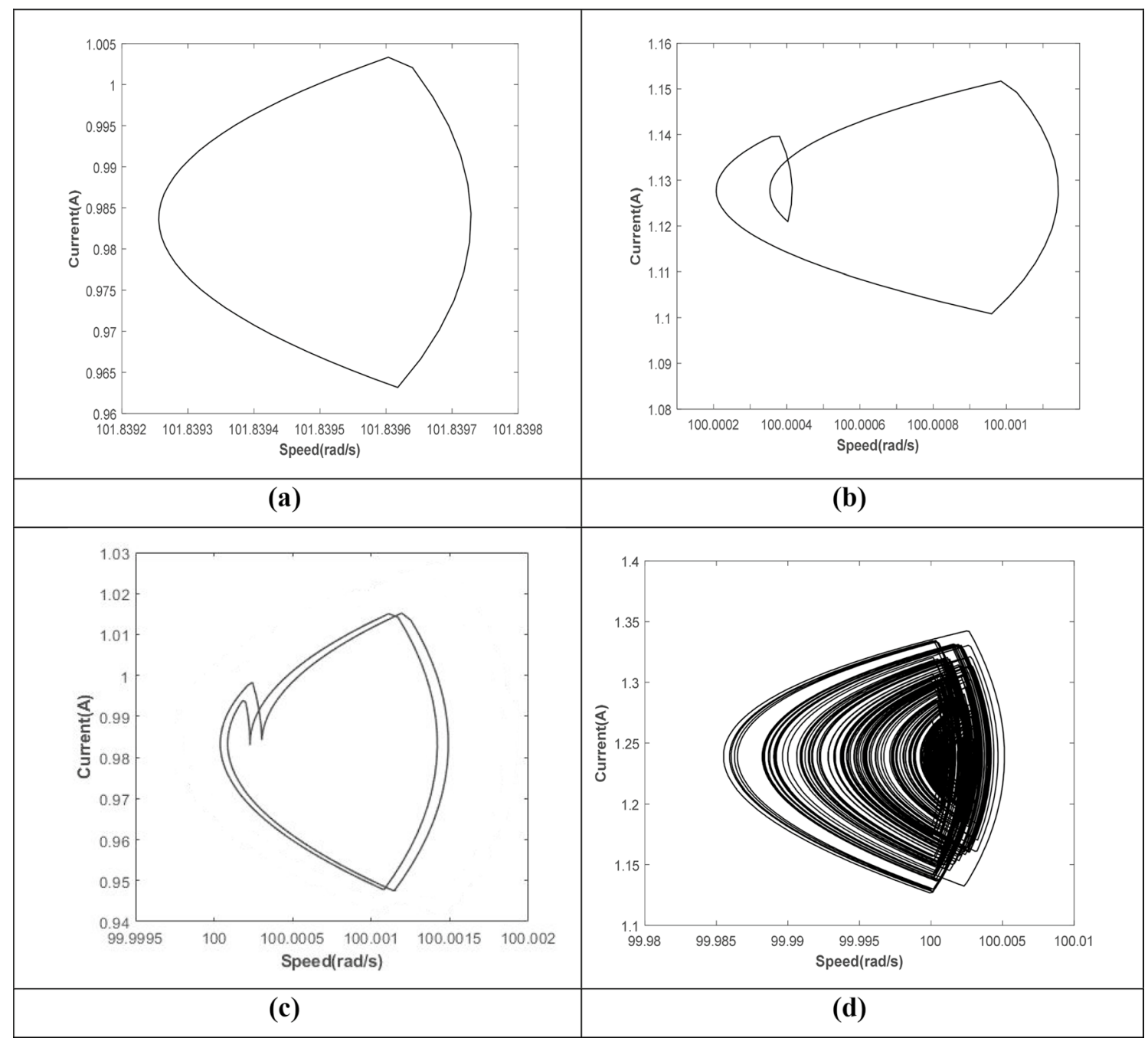

Fig. 3 a Period-1, b period-2, c period-4 and $\mathbf{d}$ chaos trajectories due to changing load torque 
Table 1 Modulus of the Floquet multipliers when changing load torque

\begin{tabular}{|c|c|c|c|}
\hline$T_{L}$ & $S$ & $M(T, 0)$ & $\begin{array}{l}\text { Modulus (Flo- } \\
\text { quet multipli- } \\
\text { ers) }\end{array}$ \\
\hline 0.087 & {$\left[\begin{array}{cc}1.0000 & 0 \\
-42.4887 & 1.0000\end{array}\right.$} & $\begin{array}{cc}-1.8778 & 0.0232 \\
-40.0741 & -0.0025\end{array}$ & $\begin{array}{l}0.9617 \\
0.9617\end{array}$ \\
\hline 0.099 & $\begin{array}{cc}1.0000 & 0 \\
-43.0438 & 1.0000\end{array}$ & $\begin{array}{cc}-1.9154 & 0.0223 \\
-40.5975 & -0.0096\end{array}$ & $\begin{array}{l}0.9999 \\
0.9250\end{array}$ \\
\hline 0.1 & {$\left[\begin{array}{cc}1.0000 & 0 \\
-43.0582 & 1.0000\end{array}\right.$} & $\begin{array}{cc}-1.9164 & 0.0223 \\
-40.6111 & -0.0099\end{array}$ & $\begin{array}{l}1.0146 \\
0.9117\end{array}$ \\
\hline
\end{tabular}

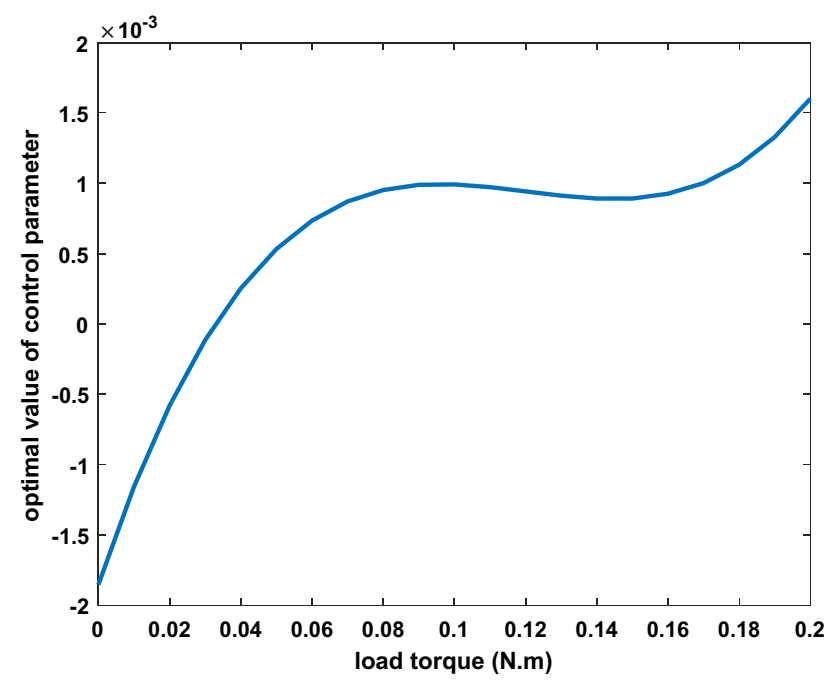

Fig. 4 Relationship between $\alpha$ and $T_{L}$

\section{The controller}

\section{Control by developing the Floquet theory}

Stabilization of the system using Floquet theory was discussed in [26, 30, 37-39]. This technique is used to handle the effects of bifurcation and chaos that occur as a result of changing the torque of the load by forcing the path to be in period -1 (steady-state). Keeping the modulus of Floquet multipliers less than 1 by changing $\omega_{\text {ref }}$ to $\omega_{\text {ref }}(1+\alpha \sin (\omega t)) ; \alpha$ is a control parameter, a very small signal which leads to change the value of $S$ by changing $\frac{\partial h}{\partial t}$ :

$\frac{\partial h}{\partial t}=-\omega_{r e f} \times \alpha \times \omega \cos \left(\omega t_{\varepsilon}\right)-\frac{\left(V_{U}-V_{L}\right)}{T \times K_{P}}$.

The relationship between $\alpha$ and $T_{L}$ is presented in Fig. 4: $\alpha\left(T_{L}\right)=1.8235 T_{L}^{3}-0.65887 T_{L}^{2}+0.0761 T_{L}-0.0018526$.

Adding the supervisory controller is presented in Fig. 5. The control signal becomes

$V_{c o n}(t)=K_{P}\left(\omega(t)-\omega_{r e f}(1+\alpha \sin (\omega t))\right)$.

Controlling the system using the Floquet theory, the problem of bifurcation, which leads to chaos, is solved. Consequently, it makes the system in period-1 trajectory when changing the load torque. However, there is a steady-state error $\left(e_{\mathrm{ss}}=0.1 \%\right)$, overshoot, undershoot, and oscillation when altering the load torque, as shown in Fig. 6.

\section{PI Fuzzy controller}

Fuzzy logic controller (FLC) clarifies the experience and the knowledge of a human operator in linguistic variables (fuzzy rules) without any knowledge of parameter variations and dynamics of the system. Implementation of FLC depends upon the process done by human factors without the need for a mathematical model [41-46]. The fuzzy system consists of two inputs: the error and the change of error, and one output is the change of control output. The structure of the PI-fuzzy controller is shown in Fig. 7.
Fig. 5 Block diagram of the drive system with a supervisory controller

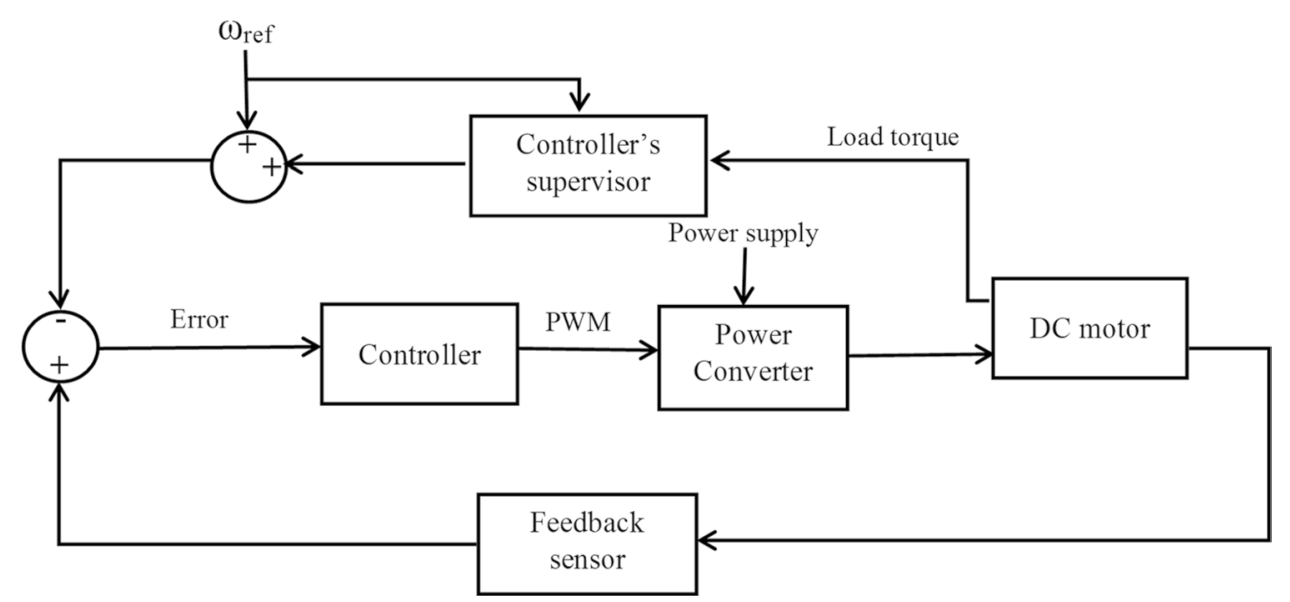



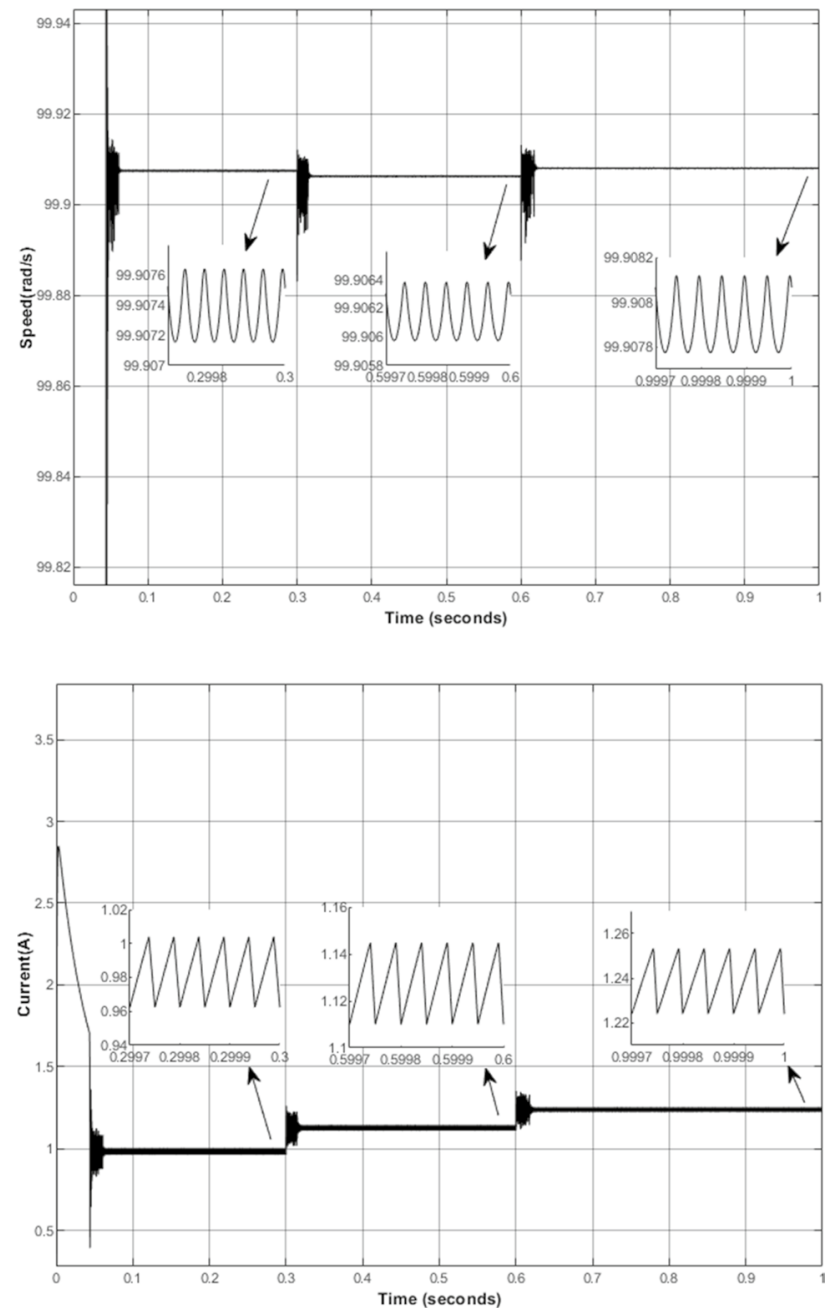

Fig. 6 Waveforms for speed and current with changing load torque by developing Floquet theory

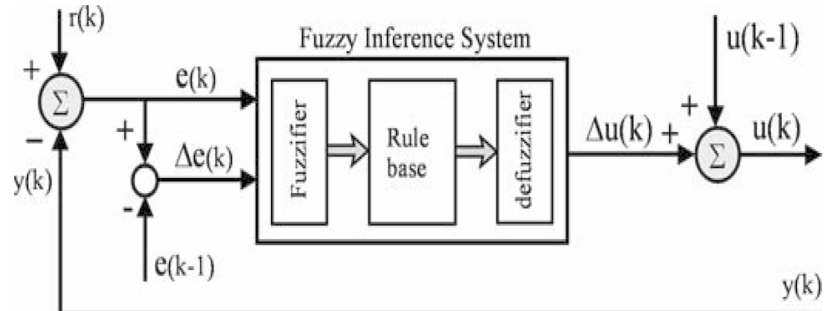

Fig. 7 Structure of the PI-fuzzy controller

The fuzzy rules make feasible changes to obtain the minimum error by deciding whether an increase or decrease $\Delta \mathrm{u}(\mathrm{k})$ based on $(\mathrm{e}(\mathrm{k})$ and $\Delta \mathrm{e}(\mathrm{k}))$, the sets of $\mathrm{e}(\mathrm{k}), \Delta \mathrm{e}(\mathrm{k})$ and $\Delta \mathrm{u}(\mathrm{k})$ are $\{\mathrm{NB}$ (negative big), NS(negative small), ZZ(zero), $\mathrm{PS}$ (positive small) and $\mathrm{PB}$ (positive big) $\}$. The fuzzy rule base is presented in Table 2.
Table 2 Fuzzy rule base

\begin{tabular}{llllll}
\hline$\Delta e l e$ & $\mathrm{NB}$ & $\mathrm{NS}$ & $\mathrm{ZZ}$ & $\mathrm{PS}$ & $\mathrm{PB}$ \\
\hline $\mathrm{NB}$ & $\mathrm{NS}$ & $\mathrm{NS}$ & $\mathrm{NB}$ & $\mathrm{NB}$ & $\mathrm{ZZ}$ \\
$\mathrm{NS}$ & $\mathrm{NS}$ & $\mathrm{NB}$ & $\mathrm{NB}$ & $\mathrm{ZZ}$ & $\mathrm{PS}$ \\
$\mathrm{ZZ}$ & $\mathrm{NB}$ & $\mathrm{NB}$ & $\mathrm{ZZ}$ & $\mathrm{PS}$ & $\mathrm{PS}$ \\
$\mathrm{PS}$ & $\mathrm{NB}$ & $\mathrm{ZZ}$ & $\mathrm{PS}$ & $\mathrm{PS}$ & $\mathrm{PB}$ \\
$\mathrm{PB}$ & $\mathrm{ZZ}$ & $\mathrm{PS}$ & $\mathrm{PS}$ & $\mathrm{PB}$ & $\mathrm{PB}$
\end{tabular}
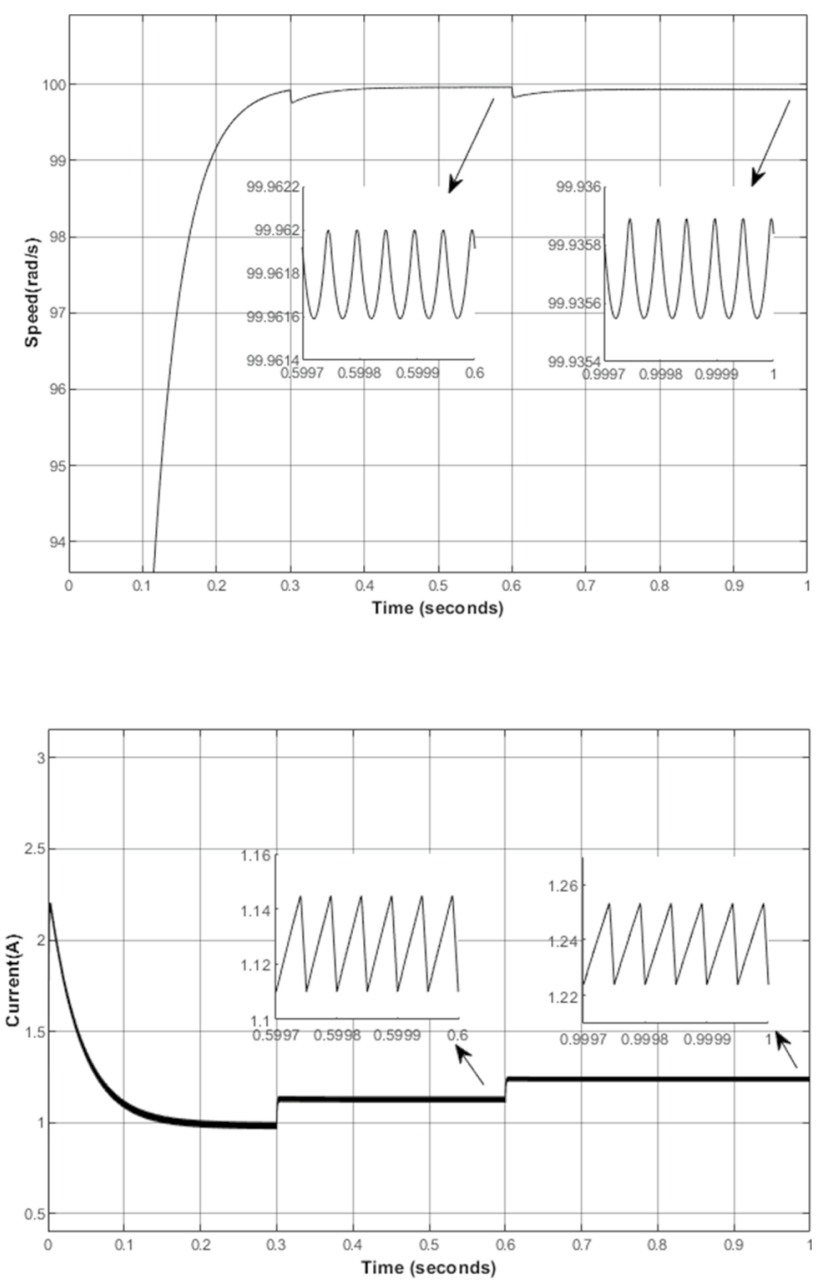

Fig. 8 Waveforms for speed and current with changing load torque based on PI fuzzy controller

\section{System dynamic behavior with the PI fuzzy controller when changing the load torque}

The time-domain waveform and phase portrait (trajectories in the phase plane) indicate the stability of the system. Waveforms of period-1 speed and current when changing load torque are depicted in Fig. 8. At $V_{\text {in }}=24 \mathrm{~V}$ and $T_{\mathrm{L}}=0.087 \mathrm{Nm}$, the steady-state error is very small $\left(e_{\mathrm{ss}}=0.04 \%\right)$ and the system is still in the stable state when 


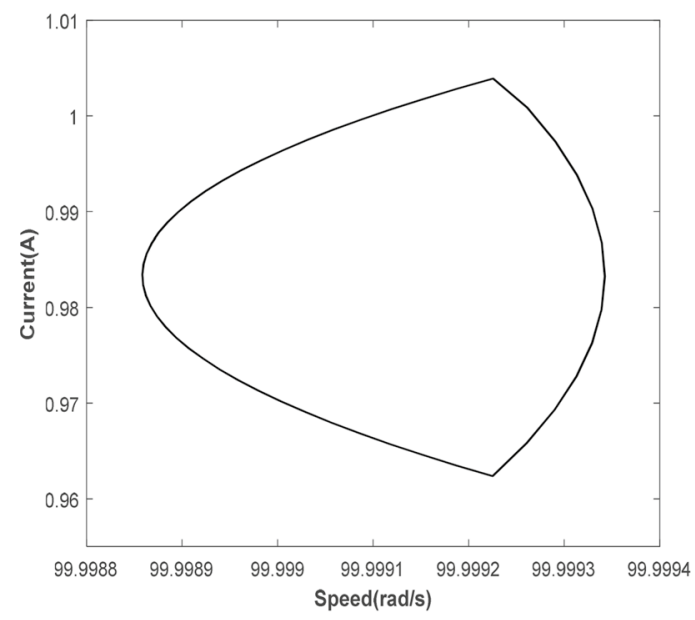

(a)

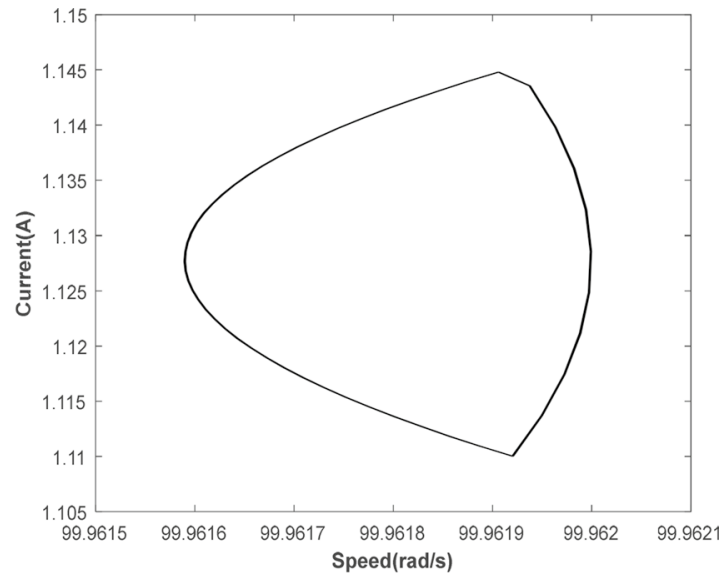

(b)

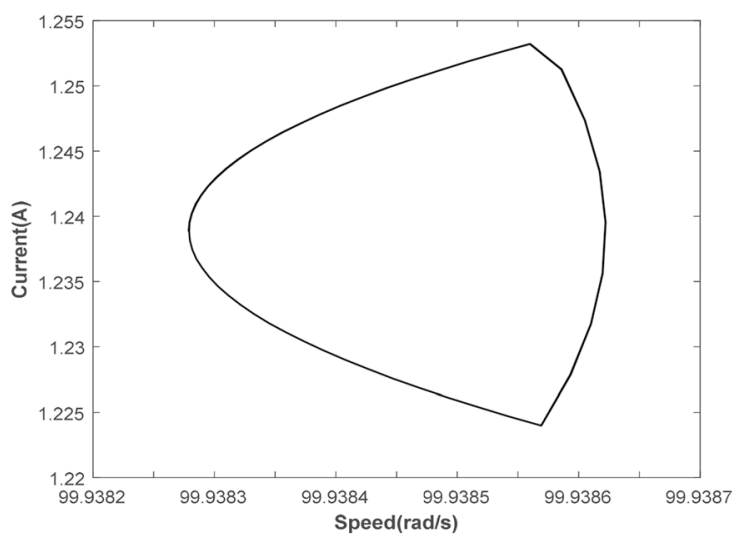

(c)

Fig. 9 a Period- 1 at $T_{L}=0.087 \mathrm{Nm}$, b period- 1 at $T_{L}=0.1 \mathrm{Nm}$ and $\mathbf{c}$ period- 1 at $T_{L}=0.11 \mathrm{Nm}$ trajectories based on PI-fuzzy controller

changing the load torque at $0.3 \mathrm{~s}$ to $T_{\mathrm{L}}=0.1 \mathrm{~N} . \mathrm{m}$, as shown in Fig. 8. FLC improves the time response and solves the problem of period-doubling bifurcation, overshoot, and oscillation.

A further variation of the load torque at $0.6 \mathrm{~s}$ to $T_{\mathrm{L}}=0.11$ $\mathrm{Nm}$, the steady-state error is still very small $\left(e_{\mathrm{ss}}=0.06 \%\right)$, also the system still in the stable state, as shown in Fig. 8. FLC solves the problem of chaos, overshoot, and oscillation. It consequently improves the time response when changing the load torque at $0.6 \mathrm{~s}$. Period- 1 trajectories at $T_{\mathrm{L}}=0.087$ $\mathrm{Nm}, T_{\mathrm{L}}=0.1 \mathrm{Nm}$, and $T_{\mathrm{L}}=0.11 \mathrm{Nm}$ is presented in Fig. 9 .

\section{Conclusion}

The non-linearity effect of a dynamical system is the main problem to achieve the speed control of PMDC drive. When changing the load torque of the motor, the system loses its stability and period-doubling bifurcation occurs, which leads to chaos and can damage the system. Control the system by developing the Floquet theory, solve the problem of bifurcation but there are overshoot and oscillation when changing the load torque. Adding a PI-fuzzy controller makes the speed control smoother and ensures the system's stability when changing the load torque. The simulation results show that FLC gives a better response than that obtained when applying the other controller and tends to vanish steady-state error furthermore, removes the overshoot and the oscillation of the system. MATLAB/SIMULINK software is used to validate the model.

Open Access This article is licensed under a Creative Commons Attribution 4.0 International License, which permits use, sharing, adaptation, distribution and reproduction in any medium or format, as long as you give appropriate credit to the original author(s) and the source, provide a link to the Creative Commons licence, and indicate if changes 
were made. The images or other third party material in this article are included in the article's Creative Commons licence, unless indicated otherwise in a credit line to the material. If material is not included in the article's Creative Commons licence and your intended use is not permitted by statutory regulation or exceeds the permitted use, you will need to obtain permission directly from the copyright holder. To view a copy of this licence, visit http://creativecommons.org/licenses/by/4.0/.

\section{References}

1. Čermák J, Nechvátal L (2019) Stability and chaos in the fractional Chen system. Chaos Solitons Fractals 125:24-33. https:// doi.org/10.1016/j.chaos.2019.05.007

2. Mehrjooee O, FathollahiDehkordi S, HabibnejadKorayem M (2020) Dynamic modeling and extended bifurcation analysis of flexible-link manipulator. Mech Based Design Struct Mach 48(1):87-110. https://doi.org/10.1080/15397734.2019.1665542

3. Lai Q, Wan Z, KamdemKuate PD, Fotsin H (2020) Coexisting attractors, circuit implementation, and synchronization control of a new chaotic system evolved from the simplest memristor chaotic circuit. Commun Nonlinear Sci Numer Simul 89:105341. https:// doi.org/10.1016/j.cnsns.2020.105341

4. Lai Q, KamdemKuate PD, Liu F, Iu HHC (2020) An extremely simple chaotic system with infinitely many coexisting attractors. IEEE Trans Circuits Syst II Express Briefs 67(6):1129-1133. https://doi.org/10.1109/TCSII.2019.2927371

5. Lai Q, Norouzi B, Liu F (2018) Dynamic analysis, circuit realization, control design, and image encryption application of an extended Lü system with coexisting attractors. Chaos Solitons Fractals 114:230-245. https://doi.org/10.1016/j.chaos .2018.07.011

6. Sathiyadevi K, Karthiga S, Chandrasekar VK, Senthilkumar DV, Lakshmanan M (2019) Frustration induced transient chaos, fractal and riddled basins in coupled limit-cycle oscillators. Commun Nonlinear Sci Numer Simul 72:586-599. https://doi. org/10.1016/j.cnsns.2019.01.024

7. Orlando D, Gonçalves PB, Rega G, Lenci S (2019) Influence of transient escape and added load noise on the dynamic integrity of multistable systems. Int J Non-Linear Mech 109(2018):140-154. https://doi.org/10.1016/j.ijnonlinmec.2018.12.001

8. Quan Y, Yang X (2019) Lyapunov exponent-based study of chaotic mechanical behavior of concrete under compression. AdvCivEng. https://doi.org/10.1155/2019/7495014

9. Roy A, Misra AP, Banerjee S (2019) Chaos-based image encryption using vertical-cavity surface-emitting lasers. Optik. https:// doi.org/10.1016/j.ijleo.2018.09.062

10. Hekimoglu B (2019) Optimal tuning of fractional order PID controller for DC motor speed control via chaotic atom search optimization algorithm. IEEE Access. https://doi.org/10.1109/ACCES S.2019.2905961

11. Alawida M, Samsudin A, Teh JS (2020) Enhanced digital chaotic maps based on bit reversal with applications in random bit generators. Inf Sci. https://doi.org/10.1016/j.ins.2019.10.055

12. Demidova LA, Gorchakov AV (2020) A study of chaotic maps producing symmetric distributions in the fish school search optimization algorithm with exponential step decay. Symmetry. https ://doi.org/10.3390/sym12050784

13. Korolj A, Wu HT, Radisic M (2019) A healthy dose of chaos: Using fractal frameworks for engineering higher-fidelity biomedical systems. Biomaterials. https://doi.org/10.1016/j.biomateria 1s.2019.119363

14. Boukhalkhal AL, Kadi MEA, Lasbet Y, Loubar K, Awad S, Makhlouf M, Tazerout M (2019) A continuous biodiesel production process using a chaotic mixer-reactor. Waste Biomass Valoriz. https://doi.org/10.1007/s12649-019-00880-x

15. Soufiani BN, Salamci MU (2018) Effect of delay of immune system response in cancer dynamics: bifurcation and chaos analysis. In: MED 2018 - 26th Mediterranean Conference on Control and Automation. https://doi.org/10.1109/MED.2018.8442856

16. Farajzadeh MA, Tohidi A (2019) Mixing and heat transfer enhancement of power-law fluids inside helically coiled tube by chaotic advection. J Nonnewton Fluid Mech. https://doi. org/10.1016/j.jnnfm.2019.104202

17. Tahir FR, Abdul-Hassan KM, Abdullah MA, Pham VT, Hoang TM, Wang X (2017) Analysis and stabilization of chaos in permanent magnet DC motor driver. Int J Bifurc Chaos. https://doi. org/10.1142/S0218127417501735

18. Zhang R, Wu A, Wang Z, Cang S (2020) Chaotic and subharmonic oscillations in a DC-DC boost converter with PWM voltage-current hybrid controller and parallel MR load. Nonlinear Dyn 99(2):1321-1339. https://doi.org/10.1007/s11071-019-05357 $-\mathrm{Z}$

19. Zhang R, Wu A, Zhang S, Wang Z, Cang S (2018) Dynamical analysis and circuit implementation of a DC/DC singlestage boost converter with memristance load. Nonlinear Dyn 93(3):1741-1755. https://doi.org/10.1007/s11071-018-4288-9

20. Li S, Fahimi B (2018) On the period-doubling bifurcation in PWM controlled buck converter. In: 2018 IEEE Transportation Electrification Conference and Expo (ITEC), pp 589-594. https ://doi.org/10.1109/ITEC.2018.8450097

21. Xu CJ, Liao MX, Li PL (2019) Bifurcation control of a fractional-order delayed competition and cooperation model of two enterprises. Sci China Technol Sci 62(12):2130-2143. https:// doi.org/10.1007/s11431-018-9376-2

22. Wawrzaszek A, Krasińska A (2019) Hopf bifurcations, periodic windows and intermittency in the generalized Lorenz model. Int J Bifurc Chaos 29(14):1-15. https://doi.org/10.1142/S0218 127419300428

23. Xu C, Liao M, Li P, Guo Y, Xiao Q, Yuan S (2019) Influence of multiple time delays on bifurcation of fractional-order neural networks. Appl Math Comput 361:565-582. https://doi. org/10.1016/j.amc.2019.05.057

24. Bramburger JJ, Kutz JN (2020) Poincaré maps for multiscale physics discovery and nonlinear Floquet theory. Physica D 408:132479. https://doi.org/10.1016/j.physd.2020.132479

25. Breda D, Liessi D (2020) Floquet theory and stability of periodic solutions of renewal equations. J Dyn Diff Equat. https:// doi.org/10.1007/s10884-020-09826-7

26. Wang J, Lv B, Zhao Y (2018) Chaos and stability of spur gear transmission system for locomotive based on energy method and floquet theory. Hindawi Shock Vib. https://doi. org/10.1155/2018/5691892

27. Gkizas G, Giaouris D, Pickert V (2019) A new method on the limit cycle stability analysis of digitally controlled interleaved DC-DC converters. Control EngPrac 90(July):111-122. https ://doi.org/10.1016/j.conengprac.2019.06.012

28. Guo L, Zhang K, Pan H (2019) The stability analysis of DC-DC conversion systems based on Monodromy Matrix. In: Chinese Control And Decision Conference (CCDC), Nanchang, China, 2019, pp 4244-4248. https://doi.org/https://doi.org/10.1109/ CCDC.2019.8832891

29. Chen D, Xie S, Huang X, Chen Y (2019) Calculating floquet multipliers for periodic solution of non-smooth dynamical system. In: 2019 International Conference on Applied Mathematics, Modeling, Simulation, and Optimization (AMMSO 2019), pp 27-33. https://doi.org/10.12783/dtcse/ammso2019/30101

30. Morel C, Morel JY, Danca MF (2018) Generalization of the Filippov method for systems with a large periodic input. Math Comput Simul 146:1-13. https://doi.org/10.1016/j.matcom.2017.09.004 
31. Huynh BH, Tjahjowidodo T, Zhong ZW, Wang Y, Srikanth N (2017) Comparative study of full state variables and time-delay coordinates OGY chaos control for bi-stable vortex-induced vibration energy harvesters. In: IEEE/ASME International Conference on Advanced Intelligent Mechatronics, AIM. https://doi.org/https ://doi.org/10.1109/AIM.2017.8014238

32. Huang J, Jing Z (2019) Feedback control of unstable periodic motion for brushless motor with unsteady external torque. Eur Phys J Spec Top 228(9):1809-1822. https://doi.org/10.1140/epjst /e2019-800223-1

33. Avanço RH, Tusset AM, Balthazar JM, Nabarrete A, Navarro HA (2018) On nonlinear dynamics behavior of an electro-mechanical pendulum excited by a nonideal motor and a chaos control taking into account parametric errors. J BrazSocMech Sci Eng. https:// doi.org/10.1007/s40430-017-0955-x

34. Sarkar SK, Das SK (2018) High performance nonlinear controller design for AC and DC machines: partial feedback linearization approach. Int J Dyn Control 6(2):679-693. https://doi. org/10.1007/s40435-017-0330-x

35. Wu H, Pickert V, Giaouris D, Ji B (2017) Nonlinear analysis and control of interleaved boost converter using real-time cycle to cycle variable slope compensation. IEEE Trans Power Electron 32(9):7256-7270. https://doi.org/10.1109/TPEL.2016.2626119

36. Li S, Chen T (2019) Nonlinear dynamics in the switched reluctance motor drive with time-delay feedback control. In: 2019 IEEE Texas Power and Energy Conference (TPEC), pp 1-6. https ://doi.org/10.1109/TPEC.2019.8662177

37. Zhou P, Cai H, Yang C (2016) Stabilization of the unstable equilibrium points of the fractional-order BLDCM chaotic system in the sense of Lyapunov by a single-state variable. Nonlinear Dyn 84(4):2357-2361. https://doi.org/10.1007/s11071-016-2649-9

38. Hu W, Zhang B, Yang R (2019) Bifurcation mechanism and stabilization of $V^{2} C$ controlled buck converter. IEEE Access 7:7717477182. https://doi.org/10.1109/ACCESS.2019.2918297

39. Han Y, Lin X, Fang X, Xu L, Yang P, Hu W, Blaabjerg F (2020) Floquet theory-based small-signal stability analysis of singlephase asymmetric multilevel inverters with SRF voltage control. IEEE Trans Power Electron 35(3):3221-3241. https://doi. org/10.1109/TPEL.2019.2930326

40. Zadeh LA (1996) Fuzzy logic = computing with words. IEEE Trans Fuzzy Syst. https://doi.org/10.1109/91.493904

41. Fu CB, Tian AH, Yu KN, Lin YH, Yau HT (2018) Analyses and control of chaotic behavior in DC-DC converters. Math Problems Eng. https://doi.org/10.1155/2018/7439137

42. Wen SH, Zheng W, Jia SD, Ji ZX, Hao PC, Lam HK (2020) Unactuated force control of 5-DOF parallel robot based on fuzzy PI. Int
J Control AutomSyst 18(X):1-12. https://doi.org/10.1007/s1255 5-018-0579-7

43. Precup RE, Tomescu ML (2015) Stable fuzzy logic control of a general class of chaotic systems. Neural Comput Appl 26(3):541550. https://doi.org/10.1007/s00521-014-1644-7

44. Tiwari N, Tiwari AN (2019) Design and control of Buck converter using PID and Fuzzy logic controller. In: 2018 International Conference on Power Energy, Environment and Intelligent Control, PEEIC 2018, pp 557-564. https://doi.org/10.1109/PEEIC .2018 .8665621

45. Harrouz A, Nourdine K, Kayisli K, Bulbul HI, Colak I (2018) A fuzzy controller for stabilization of asynchronous machine. In: 7th International IEEE Conference on Renewable Energy Research and Applications, ICRERA 2018, 5, pp 1369-1373. https://doi. org/10.1109/ICRERA.2018.8566814

46. Tam LM, Chen HK, Li SY (2018) Adaptive synchronization of complicated chaotic systems with uncertainties via fuzzy modeling-based control strategy. Inf Sci 427:18-31. https://doi. org/10.1016/j.ins.2017.10.028

47. Rasheed A, Khan S, Gelani HE, Dastgeer F (2019) AC vs. DC home: an efficiency comparison. In: RAEE 2019-International Symposium on Recent Advances in Electrical Engineering, 4, pp 1-6. https://doi.org/10.1109/RAEE.2019.8887064

48. Lee DH (2020) Combined sensor-sensorless control of PMDC motor for HD camera of unmanned monitoring system. J ElectrEngTechnol 15(1):27-35. https://doi.org/10.1007/s42835-01900310-X

49. Li Y, Xue Q, He J, Zhao T (2018) Design of music toy car based on smart phone via Bluetooth remote control. In: Proceedings of 2018 2nd IEEE Advanced Information Management, Communicates, Electronic and Automation Control Conference, IMCEC 2018, (Imcec), pp 1976-1980. https://doi.org/10.1109/IMCEC .2018 .8469311

50. Somwong S, Mano A (2020) Automatic fruit syrup mixing machine. In: 2020 8th International Electrical Engineering Congress, IEECON 2020, 0-3. https://doi.org/https://doi.org/10.1109/ iEECON48109.2020.229519

51. Torun Y, Öztürk A (2020) A new breakthrough detection method for bone drilling in robotic orthopedic surgery with closed-loop control approach. Ann Biomed Eng 48(4):1218-1229. https://doi. org/10.1007/s10439-019-02444-5

Publisher's Note Springer Nature remains neutral with regard to jurisdictional claims in published maps and institutional affiliations. 